\title{
Central Serous Chorioretinopathy Following Oral Use of Adulterated Honey Mixed with Tadalafil: A Case Report
}

\author{
Khalid S Asharari (D) \\ Naif M Alali ${ }^{2}$ \\ Moustafa S Magliyah' \\ Hassan A Al-Dhibi ${ }^{3}$ \\ Faisal A Almarek ${ }^{4}$ \\ Hani B AlBalawi ${ }^{2}$ \\ 'Department of Ophthalmology, Prince \\ Mohammed Medical City, Aljouf, Saudi \\ Arabia; ${ }^{2}$ Ophthalmology Division, \\ Department of Surgery, Faculty of \\ Medicine, University of Tabuk, Tabuk, \\ Saudi Arabia; ${ }^{3}$ Vitreoretinal Division, King \\ Khaled Eye Specialist Hospital, Riyadh, \\ Saudi Arabia; ${ }^{4}$ Department of \\ Ophthalmology, College of Medicine, \\ Imam Mohammad bin Saud Islamic \\ University, Riyadh, Saudi Arabia
}

Correspondence: Hani B AlBalawi Ophthalmology Division, Department of Surgery, Faculty of Medicine, University of Tabuk, Tabuk, Saudi Arabia

Email hani.albalawi@hotmail.com
Background: Central serous chorioretinopathy (CSCR) is an idiopathic condition characterized by serous retinal detachment and/or retinal pigment epithelial (RPE) detachment, the condition associated with a fluid leak through the RPE into subretinal space. This article reports on an unusual case of CSCR following taking adulterated honey mixed with tadalafil powder.

Case Presentation: A 38-year-old male, not known to have any medical illnesses, came to our ophthalmology clinic complaining of sudden onset of blurred central vision in the left eye for five days after taking an adulterated honey which was claimed to improve sexual performance. On taking a history, the patient denied taking any medications or past eye trauma or surgery. On detailed ophthalmologic examination, the best-corrected visual acuity (BCVA) was 20/20 in the right eye and 20/80 in the left eye. Dilated fundus examination of the right eye showed a flat retina, normal macular reflex, healthy optic nerve head and the left eye showed blunt foveal reflex with neurosensory retinal detachment at the macula and subretinal fluid. Optical coherence tomography (OCT) of the left eye showed marked macular thickening, leading to the impression of central serous chorioretinopathy (CSCR). Four weeks after stopping the adulterated honey, BCVA improved to 20/20 in the left eye, with complete resolution of subretinal fluids.

Conclusion: Our case adds to recently reported cases of a link between tadalafil and CSCR. Keywords: tadalafil, CSCR, sildenafil, adulterated honey

\section{Background}

Central serous chorioretinopathy (CSCR) is an idiopathic condition characterized by serous retinal detachment and/or retinal pigment epithelial (RPE) detachment, the condition associated with a fluid leak through the RPE into subretinal space. ${ }^{1}$ The exact etiology of the CSCR has not been elucidated; however, many associated risk factors have been found, like steroid use, ${ }^{2}$ type A personality, ${ }^{3}$ and pregnancy. ${ }^{4}$

A selective inhibitor of cGMP-specific phosphodiesterase type 5 (PDE-5) medication groups like sildenafil (Viagra@) and tadalafil (Cialis@) are widly used in the treatment of male sexual dysfunction. ${ }^{5}$ It is well known to cause several ocular manifestations such as a bluish visual flash, ocular pain, a transient decrease of visual acuity, and conjunctival injections. ${ }^{6}$

Fraunfelder et al reported that sildenafil could lead to an increase in vascular permeability, particularly at high doses, and, in turn, this can lead to CSCR if increased choroidal vascular permeability occurs. ${ }^{7}$ This article reports on an 
unusual case of CSCR following taking adulterated honey mixed with tadalafil powder, characterized by macular elevation, serous retinal detachment, and decreased vision.

\section{Case Report}

A 38-year-old male, not known to have any medical illnesses, presented to our ophthalmology clinic complaining of blurred vision in the left eye for five days. On past medical history, no history of taking any systemic medications or prior eye trauma or surgery were evident. On detailed ophthalmologic examination, best-corrected visual acuity (BCVA) in the right eye was 20/20 and in the left eye was 20/80, intraocular pressure was $15 \mathrm{mmHg}$ in both eyes, normal color vision was evident in both eyes, there was no afferent pupillary defect (APD), the confrontation visual field was fully normal in both eyes, and there was full normal extra-ocular muscle function in both eyes. Anterior segment examination of both eyes revealed normal cornea, deep and quiet anterior chamber; the iris was round and regular, and the lens was clear. Dilated fundus examination of the right eye showed flat retina, normal macular reflex, healthy optic nerve head and the left eye showed blunt foveal reflex with neurosensory retinal detachment at the macula and subretinal fluid, leading to the impression of central serous chorioretinopathy (CSCR).

Upon acquiring further history from the patient, he denied having features of type A personality or using steroids. However, he reported that blurred vision was preceded by using a special type of honey that he used to improve sexual function. On search back about that indigested honey, we found a recent announcement by the Saudi food and drug authority to stop using it because it was adulterated by tadalafil. ${ }^{8}$

Optical coherence tomography (OCT) of the left eye on presentation confirmed the diagnosis of CSCR (Figure 1). Four weeks after stopping taking the adulterated honey, BCVA in the left eye improved to 20/20 with a flat retina and no subretinal fluid. OCT was repeated, which confirmed the complete resolution of CSCR (Figure 2).

\section{Discussion and Conclusions}

In 1866 Albrecht von Graefe first recognized central serous chorioretinopathy, and he named it central recurrent retinitis. ${ }^{9}$ Since that time, several reports emerged in literature with different names such as idiopathic flat detachment of the macula, ${ }^{10}$ central serous retinopathy, ${ }^{11}$ central angiospastic retinopathy, and others. ${ }^{12}$ In 1967 the

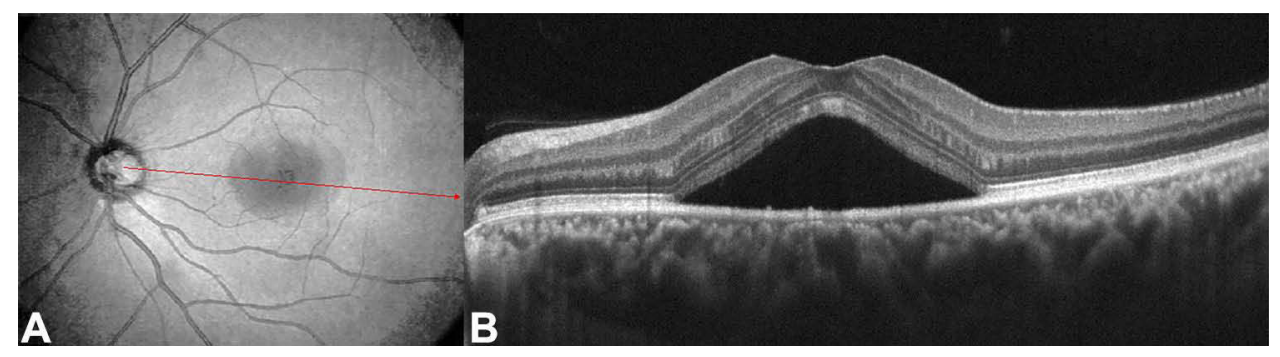

Figure I (A) is a red-free photo of the left eye showing neurosensory retinal detachment. (B) is a spectral-domain optical coherence tomography (SD-OCT) showing subretinal fluids underlying the detached neurosensory retina; a red arrow indicates the location of OCT cut.

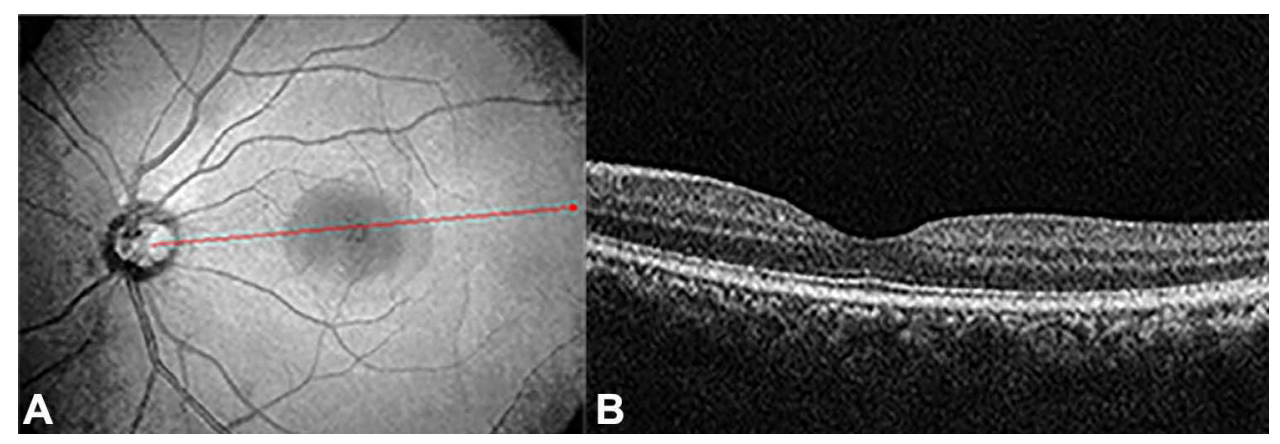

Figure $2(\mathbf{A})$ is a red-free photo of the left eye showing attached retina. (B) is a spectral-domain optical coherence tomography (SD-OCT) showing resolved subretinal fluids; a red arrow indicates the location of OCT cut. 
condition was named idiopathic central serous chorioretinopathy (CSCR) by Gass et al. ${ }^{13}$ CSCR is an idiopathic condition characterized by serous retinal detachment and/ or retinal pigment epithelial (RPE) detachment. ${ }^{1}$ The condition is most commonly seen in men more than women and at age ranges from middle age to early elderly age. ${ }^{14}$ Most CSCR patients, around $85 \%$, are associated with an excellent visual prognosis and spontaneously regain the vision within one to six months. ${ }^{15} \mathrm{CSCR}$ can be presented with broad symptoms that may include sudden onset painless blurred central vision, relative central scotoma, metamorphopsia, and others.

PDE inhibitors medication groups are well known to cause several ocular manifestations such as bluish visual flash, ocular pain, transient decreased visual acuity, conjunctival injections, and temporary alterations in electroretinogram (ERG). ${ }^{16}$ However, many types of PDE have been reported in different tissues. In the retina, PDE type 6 exists and plays a critical role in visual function, ${ }^{17}$ and it is assumed that it is a basis for abnormal color vision. On the other hand, its effect on PDE type 5 leads to increased cGMP level, increased smooth muscle relaxation in vascular tissues, and increased blood inflow; this can lead to systemic vascular dilatation and also increased choroidal thickness. ${ }^{15}$ Vance et al reported that sildenafil increases choroidal thickness as evidenced by measurement of choroid by enhanced depth OCT. ${ }^{18}$ Therefore, this medication shares with CSCR patients its ability to increase choroidal thickness, as evident in CSCR patients.

In our reported case, the patient used adulterated honey mixed with tadalafil powder from an unauthorized dealer; the buyer claimed that it is natural honey and has a natural ability to increase sexual function. It is most likely that the frequent use of adulterated honey with tadalafil powder with an uncalculated dose leads to increased choroidal circulation and possible serous fluid extravasation with subsequent serous detachment. On the other hand, fast, dramatic improvement of the condition subjectively and objectively could be a strong indicator of the association. Our case adds to recently reported cases of a link between tadalafil and CSCR. Finally, this case gives an example of the importance of taking a detailed history, remaining highly suspicious of all information provided by the patient, and of linking it to clinical presentation.

\section{Abbreviations}

BCVA, best-corrected visual acuity; CSCR, central serous chorioretinopathy; OCT, optical coherence tomography; RPE, retinal pigment epithelium.

\section{Data Sharing Statement}

Data sharing is not applicable to this article as no datasets were generated or analyzed during the current study.

\section{Ethics Approval and Consent to Participate}

This study was exempted from ethical approval by the Institutional Review Board at the University of Tabuk. The reported patient consented to be included in the study and to its publication.

\section{Consent for Publication}

Written informed consent was obtained from the patient for publication of this case report study with all accompanying images. Copies of the written consent are available.

\section{Funding}

There was no funding involved in this study. Each of the authors involved in this study has no financial disclosures.

\section{Disclosure}

The authors declare that they have no competing interests. Each of the authors involved in this study has no proprietary interest.

\section{References}

1. Nicholson B, Noble J, Forooghian F, Meyerle C. Central serous chorioretinopathy: update on pathophysiology and treatment. Surv Ophthalmol. 2013;58(2):103-126. doi:10.1016/j.survophthal.2012. 07.004

2. Garg S, Dada T, Talwar D, Biswas N. Endogenous cortisol profile in patients with central serous chorioretinopathy. $\mathrm{Br} J$ Ophthalmol. 1997;81(11):962-964. doi:10.1136/bjo.81.11.962

3. Yannuzzi LA. Type-A behavior and central serous chorioretinopathy. Retina. 1987;7(2):111-131. PMID: 3306853. doi:10.1097/00006982198700720-00009

4. Haimovici R, Koh S, Gagnon DR, Lehrfeld T, Wellik S. Risk factors for central serous chorioretinopathy: a case-control study. Ophthalmology. 2004;111(2):244-249. doi:10.1016/j.ophtha.2003.09.024

5. Krishnappa P, Fernandez-Pascual E, Carballido J, MartinezSalamanca JI. Sildenafil/Viagra in the treatment of premature ejaculation. Int $J$ Impot Res. 2019;31(2):65-70. PMID: 30837718. doi:10.1038/s41443-018-0099-2

6. Kumari R, Kumar N, Hazra S, Paul UK, Bandyopadhyay A. Ocular Side effects of sildenafil: a prospective study. Int J Sci Stud. 2016;4 (7):75-78.

7. Fraunfelder FW, Fraunfelder FT. Central serous chorioretinopathy associated with sildenafil. Retina. 2008;28(4):606-609. doi:10.1097/ IAE.0b013e $31815 \mathrm{ec} 2 \mathrm{c} 8$

8. Saudi Food and Drug Authority. Available from: https://old.sfda.gov. sa/en/drug/news/pages/homenews19-03-2014a1.aspx. Accessed November 5, 2021.

9. von Graefe A. Ueber centrale reccidivirende retinitis. Albert Von Graefe's Arch Ophthalmol. 1866;12:211-215. 
10. Walsh FB, Sloan LL. Idiopathic flat detachment of the macula. Am $J$ Ophthalmol. 1936;19:195-208. doi:10.1016/S0002-9394(36) 91051-6

11. Straatsma BR, Allen RA, Pettit TH. Central serous retinopathy. Trans Pacif Cst Oto Ophthalmol Soc. 1966;47:107-127.

12. Gifford SR, Marquardt G. Central angiospastic retinopathy. Arch Ophthalmol. 1989;21:211-228. doi:10.1001/archopht.1939.00860 020015001

13. Gass JDM. Pathogenesis of disciform detachment of the neuroepithelium. II. Idiopathic central serous chorioretinopathy. $\mathrm{Am}$ J Ophthalmol. 1967;63:587-615.

14. Gäckle HC, Lang GE, Freissler KA, Lang GK. [Central serous chorioretinopathy. Clinical, fluorescein angiography and demographic aspects]. Ophthalmol Z Dtsch Ophthalmol Ges. 1998;95 (8):529-533. German.
15. Hardwig PW, Silva AO, Pulido JS. Forgotten exogenous corticosteroid as a cause of central serous chorioretinopathy. Clin Ophthalmol. 2008;2(1):199-201. doi:10.2147/opth.s2165

16. Moschos MM, Nitoda E. Pathophysiology of visual disorders induced by phosphodiesterase inhibitors in the treatment of erectile dysfunction. Drug Des Devel Ther. 2016;8:3407-3413. doi:10.2147/ DDDT.S118015

17. Estrade M, Grondin P, Cluzel J, Bonhomme B, Doly M. Effect of a cGMP-specific phosphodiesterase inhibitor on retinal function. Eur J Pharmacol. 1998;352(2-3):157-163. PMID: 9716350. doi:10.1016/ s0014-2999(98)00346-x

18. Vance SK, Imamura Y, Freund KB. The effects of sildenafil citrate on choroidal thickness as determined by enhanced depth imaging optical coherence tomography. Retina. 2011;31(2):332-335. PMID: 20975620. doi:10.1097/IAE.0b013e3181eef0ae

\section{Publish your work in this journal}

The International Medical Case Reports Journal is an international, peer-reviewed open-access journal publishing original case reports from all medical specialties. Previously unpublished medical posters are also accepted relating to any area of clinical or preclinical science. Submissions should not normally exceed 2,000 words or 4 published pages including figures, diagrams and references. The manuscript management system is completely online and includes a very quick and fair peer-review system, which is all easy to use. Visit http://www.dovepress.com/testimonials.php to read real quotes from published authors. 